\begin{tabular}{|lr|}
\hline $\begin{array}{l}\text { Social Work/Maatskaplike Werk Vol } 56 \text { No } 1 \text {; Issue } 2 \\
\text { http://socialwork.journals.ac.za/pub }\end{array}$ & doi:http://dx.doi.org/10.15270/56-1-787 \\
\hline
\end{tabular}

THE DEVELOPMENT OF A CULTURALLY-APPROPRIATE MARRIAGE ENRICHMENT PROGRAMME FOR BLACK AFRICAN MARRIED COUPLES: OVERVIEW OF PROGRAMMES

Kabaro Grace Neswiswa, Susanne Jacobs

Development of knowledge on how to support marriages cross-culturally is necessary to inform appropriate solutions, especially for South Africa, where practical marital challenges amongst Black African married couples who are considered to be high risk are noted. The focus of this narrative literature-informed overview is to provide an appraisal of existing and most effective national and international marriage enrichment (ME) programmes, couples theories and social work models as the basis for the possible development of a culturally-appropriate ME programme for Black African married couples. Findings reveal, among other things: 1) there are no culturally-appropriate and empirically evaluated ME programmes beneficial to Black African married couples in SA; 2) appropriate theory is necessary and available for integration; 3) theories recognise marriage as a system, and therefore acknowledgement of various societal structures is fundamental; 4) existing empirically tested and effective programmes supporting couples theories and social work models are suitable to be adapted to the specific context.

Ms Kabaro Grace Neswiswa, Postgraduate student, Faculty of Health Sciences, COMPRES, CCYF: Centre for Child, Youth and Family Studies (Wellington), North-West University, Potchefstroom, South Africa.

Dr Susanne Jacobs, Faculty of Health Sciences, COMPRES, CCYF: Centre for Child, Youth and Family Studies (Wellington), North-West University, Potchefstroom, South Africa.

22093915@nwu.ac.za;

sjacobs2603@gmail.com

Keywords: marriage enrichment (ME), marriage enrichment programmes (MEPs), marriage, married couple, culturallyappropriate, South Africa (SA) 



\title{
THE DEVELOPMENT OF A CULTURALLY-APPROPRIATE MARRIAGE ENRICHMENT PROGRAMME FOR BLACK AFRICAN MARRIED COUPLES: OVERVIEW OF PROGRAMMES
}

\author{
Kabaro Grace Neswiswa, Susanne Jacobs
}

Kabaro Neswiswa, ORCiD Id: 0000-0001-6890-3386

Susanne Jacobs, ORCiD Id: 0000-0002-1423-9923

Ms Kabaro Grace Neswiswa, Postgraduate student, Faculty of Health Sciences, COMPRES, CCYF: Centre for Child, Youth and Family Studies (Wellington), North-West University, Potchefstroom, South Africa.

Dr Susanne Jacobs, Faculty of Health Sciences, COMPRES, CCYF: Centre for Child, Youth and Family Studies (Wellington), North-West University, Potchefstroom, South Africa.

Keywords: marriage enrichment (ME), marriage enrichment programmes (MEPs), marriage, married couple, culturally-appropriate, South Africa (SA)

\section{INTRODUCTION AND BACKGROUND}

The literature on marriage enrichment tends to conclude that ME programmes are successful especially by empowering couples with the skills needed to build functional relationships and stronger family structures, thus preventing future problems (Schmidt, Luquet \& Gehlert, 2016; Jacobi, 2017; Quirk, Owen, Inch, France \& Berge, 2014). At the same the time literature focuses on the wide variety of participants regarding general relationship skills, but not on the specific needs (Hawkins \& Fackrell, 2010) and sociocultural factors that couples may experience in differing contexts (Mikle \& Gilbert, 2019), for example, couples who are from Black African backgrounds. The purpose of this narrative literature-informed overview is to discuss existing ME programmes, couple theories and social work models for possible use as a basis for the development of a culturally-appropriate ME programme for Black African married couples. Four ME programmes were reviewed in terms of origin, focus, format, target audience, content (described briefly) as well as effectiveness: 'PREPARE/ENRICH'; 'Getting The Love You Want' (GTLYW); 'Prevention and Relationship Enhancement Programme' (PREP 8.0) and 'Couple Communication Programme' (CCP).

Numerous challenges face Black African couples in South Africa (SA), ranging from inequality, the increase of HIV/AIDS, breakdown of family structures, increased cohabitation and high rates of unemployment (Shisana, Risher, Celentano, Zungu, Rehle, Ngcaweni \& Evans, 2016). Other challenges include gender-based violence, multiple sex partners, communication barriers between spouses resulting from cultural pressures, alcohol abuse, poverty (Speizer, Zule, Carney, Browne, Ndirangu, Wechsberg \& Medicine, 2018) and the influence of Western culture and media on traditional marital aspects (Mbunyuza-Memani, 2018). According to Statistics SA, divorce cases in SA rise every year with Black Africans affected more than White, Coloured and Indian population groups (StatisticsSA, 2014, 2015, 2016, 2018). Indeed, Black African married couples may well experience marital challenges, but the literature has little to say on how to support couples, and moreover no culturallyappropriate ME programmes to support relationships, especially amongst Black African married couples, are available. This strongly indicates that an integrative theory as a knowledge base to develop culturally-appropriate ME programmes for Black African married couples is required.

Although empirical studies indicate ME programmes to be successful at teaching couples the skills needed to create and sustain healthy relationships (Schmidt et al., 2016; Jacobi, 2017; Quirk et al., 2014; Worthington, Berry, Hook, Davis, Scherer, Griffin, Wade, Yarhouse, Ripley, Miller, Sharp, Canter \& Campana, 2015; Markman \& Rhoades, 2012), there are limitations. The literature often reports empirical studies regarding marriages and ME relationship interventions to be predominately 
conducted in Western countries with a specific focus on White populations (O'Halloran, Rizzolo, Cohen \& Wacker, 2013; Killawi, Fathi, Dadras, Daneshpour, Elmi \& Altalib, 2018; Su, Miller, Canlas, Hsiao \& Willoughby, 2015; Muro, Holliman \& Luquet, 2016b). Hence there is limited data on their effectiveness in other populations such as in SA. A similar trend is noticeable locally, where ME programmes rendered are based on Western cultures (Govender, 2008) and tend to attract mostly English- and Afrikaans-speaking couples (Swart, 2013) providing little empirical data on their success (Swart, 2013; Dunn, 2017; Govender, 2008). Moreover, for ME programmes to be considered effective as a universal prevention strategy, couples must demonstrate maintenance of skills acquired for a period of two to three years (Commerford \& Hunter, 2016). However, studies investigating the longterm effects of ME programmes are limited (Schmidt et al., 2016). To counter short-term effectiveness of $\mathrm{ME}$ programmes post-intervention follow-ups and booster programmes are needed, yet are scarce (Markman \& Rhoades, 2012; Lawson, 2008). Similarly, there is an on-going debate on whether highrisk couples do benefit from ME programmes and to what extent, despite ME programmes being preventative in nature and originally designed for couples who have fairly good marital relationships (Bradbury \& Lavner, 2012; Commerford \& Hunter, 2016). ME programmes do not necessarily target existing problems but rather focus on the strengths of couples (Schmidt et al., 2016). The literature suggests couples experiencing marital problems indeed benefit from (Fallahchai, Fallahi \& Ritchie, 2017; Quirk et al., 2014; Sager \& Sager, 2005) and are attracted to programmes (Schmidt et al., 2016, DeMaria, 2005). However, offering ME interventions, regardless of their level of risk, are likely to compromise effectiveness, wasting resources on couples who do not need ME or are less likely to benefit (Bradbury \& Lavner, 2012; Commerford \& Hunter, 2016). There is very little empirical literature verifying that ME programmes provide effective interventions for couples who are already having marital problems. Antle, Sar, Christensen, Ellers, Barbee \& Van Zyl (2013) suggest programmes should be developed specifically for high-risk couples. Another important limitation is that ME programmes are not adjusted to fit specific needs couples may experience in differing contexts, for instance, couples who are from lower socio-economic backgrounds. ME programmes extended to other cultures, for example, Black African married couples, varying in perceptions, beliefs, values, social expectations and marital needs becomes necessary (Miller, Nunes, Bean, Day, Falceto, Hollist \& Fernandes, 2014; Su et al., 2015; DuPree, Bhakta, Patel \& Dupree, 2013).

In SA numerous racial and ethnic groups coexist resulting in cultural diversity and multilingualism (Mafela, 2013; Vosloo, 2011). Cultural differences were largely influenced by political conditions during the apartheid era prior to 1994, as racial groups lived in segregated communities (Ntuli, 2012). Currently, eleven languages are officially recognised, each representing an ethnic group: Northern Sotho, Xitsonga, Tshivenda, Setswana, Southern Sotho, Isindebele, Afrikaans, English, Isizulu, Xhosa and Seswati (Meyer, 2005; Mafela, 2013; Valchev, Nel, Van De Vijver, Meiring, De Bruin \& Rothmann, 2013), constituting four population groups: Indian/Asian (2,5\%), White (7.8\%), Coloured $(8.8 \%)$ and Black African, constituting the majority $(80,9 \%)$ (Statistics-SA, 2018). Since cultures differ from one ethnic or racial group to another, societies also differ. Understanding different cultures in order to inform culturally-appropriate interventions to meet needs becomes crucial (Betsch \& Böhm, 2016; Swart, 2013; Forehand \& Kotchick, 2016; Ebner Erceg, 2015; Mataboge, Ngunyulu, Mogale, Mulaudzi \& Peu, 2015; Campos \& Kim, 2017). Interventions, to be culturally-competent, must be based on the unique culture of their clients, rather than assuming that couples experience the same marital needs, irrespective of their nationality (Miller et al., 2014; Su et al., 2015; DuPree et al., 2013). Culturally-competent interventions incorporate a range of approaches designed to improve the accessibility and effectiveness of services for people from ethnic or racial minority groups (Clifford, Mccalman, Bainbridge \& Tsey, 2015).

To be clear about terminology, it is necessary to distinguish between the terms 'cultural sensitivity', 'cultural appropriation' and 'culturally appropriate'. 'Cultural sensitivity', a common term used in social work practice, pertains to an awareness of cultural differences and similarities between people without being assigned a value such as 'positive or negative', 'better or worse' or 'right or wrong', 
simply recognising differences amongst people with no culture being 'better' than others (Aghajari, Valizadeh, Zamanzadeh, Ghahramanian \& Foronda, 2019). 'Cultural appropriation' refers to the unfair or illegal taking or usage of another culture's symbols, rituals, images or sacred philosophies by another group (Surmitis, Fox \& Gutierrez, 2018). 'Culturally appropriate' entails being respectful of the culture and cultural rights of individuals and communities (Donders, 2015). Although not common in social work practice, the term 'culturally appropriate' will be used here.

In order to develop an appropriate ME programme, it was necessary to explore, firstly, the literature on ME to identify existing gaps; secondly, to identify the existing needs of Black African married couples in context; thirdly, to identify, select and review local and international ME programmes in order to assess their relevance, applicability and effectiveness; and fourthly, to identify relevant couples theories and social work models useful as a theoretical basis.

This review hopes to fill a gap in the literature and in practice by ultimately making suggestions for the development of culturally-appropriate ME programmes. Knowledge on the effectiveness, accessibility, engagement, relevance and applicability of existing international and national ME programmes and the Black African culture will be extended. The promotion of culturally-appropriate interventions regarding marriages in various cultural contexts is grounded on the preservation of indigenous knowledge and family strengthening, and will provide Black African married couples with an opportunity to acquire the skills needed to build healthy marriages, and enhance engagement and retention (Beach, Hurt, Fincham, Franklin, Mcnair \& Stanley, 2011) and in turn prevent future problems.

Also, social workers who are working with other traditional African cultures within a SA context will benefit from the findings, since a culturally-appropriate ME programme may be adapted to other settings. Fairfax (2014) advises that clear evidence within the context of social work approaches regarding marriages based on culture yields better results economically and socially. Thus, understanding perceptions from their own cultural contexts is one way to empower social workers to respond appropriately to the needs and available resources (Mandel, 2017). Since social work practice in its theoretical foundation primarily aims to develop appropriate interventions for various target groups (Mandel, 2017), it is vital to provide adequate evidence-based interventions promoting the societal structures that sustain marriages (Fairfax, 2014).

In summary, the research problem entails, firstly, addressing the statistically proven challenges and practical needs regarding marriages in SA, in particular in Black African cultures; secondly, gleaning from the limited literature how to support couples regarding marriage, which important for building stronger family structures; thirdly, addressing the fact that no culturally-appropriate and empirically evaluated ME programmes to support relationships especially amongst Black African married couples are available; fourthly, developing and utilising integrative theory as a knowledge base to develop culturally-appropriate ME programmes for Black African married couples. Accordingly, the question guiding the research is: What are the existing international and national ME programmes, couples theories and social work models useful as a basis to develop a culturally-appropriate ME programme for Black African married couples? The aim is to provide a narrative literature-informed overview of existing ME programmes, couples theories and social work models appropriate for use as a basis to develop a culturally-appropriate ME programme for Black African married couples.

\section{METHODS}

To answer the research question, a narrative literature-informed overview was conducted. Also referred to as 'traditional' or 'non-systematic' reviews, narrative reviews summarise and analyse the literature on a specific topic in a non-systematic manner (Gregory \& Denniss, 2018), often attempting to study a range of literature in order to examine the connections and synergies between different forms of evidence (Pill \& Harvey, 2019; Gordon, 2017; Ferrari, 2015). Narrative reviews are necessary because 
they offer a breadth of literature coverage and flexibility to deal with evolving knowledge and concepts (Byrne, 2016) serving as a motivation for the selection of a suitable method in this research.

The steps described by Gregory and Denniss (2018) were followed: 1) define the topic and the audience; 2) search for and research the relevant literature; 3) be critical; and 4) find a logical structure. Following a clear definition of the topic, a comprehensive search pertaining to keywords - namely 'marriage enrichment', 'marriage enrichment programmes', 'culturally appropriate', 'marriage education', 'marriage and culture', couples, 'marriage in SA', 'couple theories' and 'social work models' - was undertaken. Scholarly and academic journals, dissertations, policies, books and publications mainly from the North-West University (NWU) institutional repository, NWU library and Google Scholar were targeted. Empirical literature from the journals Marital \& Family Therapy, Couple and Relationship Therapy and Social and Work/Maatskaplike Werk were accessed, searched and researched four times. Inclusion criteria applied pertained to 1) literature published in English;2) empirical studies published between 2010 and 2019; 3) literature before 2010, either written by an expert in the field or only if limited recent data were available; and 4) studies evaluating the effectiveness of ME programmes both locally and internationally. Critical selection and analysis of the literature was undertaken, for example, to get a sense of what each publication was about, examining titles, methods and results, and then summarising, analysing and presenting the key findings in a logical manner. The overall structure as suggested by Gregory and Denniss (2018) was followed to present the narrative review: introduction, body and conclusion.

Four ME programmes were selected for review: 1) 'PREPARE/ENRICH'; 2) 'Getting The Love You Want' (GTLYW); 3) 'Prevention and Relationship Enhancement Pogramme' (PREP 8.0); and 4) 'Couple Communication Programme' (CCP).

'PREPARE/ENRICH' and 'GTLYW' were chosen based on widespread usage both internationally and nationally as well as the availability of published literature within a SA context (Swart, 2013). 'PREP 8.0 ' and ' $\mathrm{CCP}$ ', on the other hand, were selected based on international efficacy and reputation (Jacobi, 2017) as well as availability of published empirical data. Theories based on applicability to both couples and culturally-appropriate interventions such as ME programmes reviewed are 1) family systems, 2) attachment, 3) bio-ecological systems, 4) strengths based, 5) social learning, 6) behavioural cognitive, and 7) programme development. Social work models were chosen to ensure applicability to social work practice): 1) problem solving, 2) task-centred, 3) cognitive-behavioural, and 4) solution focused.

\section{ETHICS AND LIMITATIONS OF THE REVIEW}

In order to ensure ethical considerations are met, this review is part of a study approved by the Health Research Ethics Committee (HREC) of the North-West University (NWU-00089-17-S1). Cited authors were acknowledged and properly referenced following the prescribed editorial requirements of the journal Social Work/MaatskaplikeWerk. Trustworthiness was ensured by following the steps of conducting a narrative review as described by Gregory \& Denniss (2018), making it possible for the review to be replicated. A few limitations should be noted; for one, the use of a narrative literature review raises potential problems with transferability, replicability, lack of peer-reviewed methodology and bias about suitable sources in the reviewer (Gordon, 2017; Ferrari, 2015; Byrne, 2016). In order to mitigate the limitations, identified steps as described by Gregory and Denniss (2018) were followed: 1) define the topic and the audience; 2) search and research the relevant literature; 3) be critical; and 4) find a logical structure. Secondly, although the literature on ME programmes is vast, only a limited number of programmes, theories and models were selected on the basis of their relevance and applicability in culturally-appropriate interventions.

\section{FINDINGS}

In the light of the overall aim of the review, the findings are presented below. 


\section{The nature of marriage enrichment and background}

Marriage enrichment (ME) is described interchangeably as 'marriage education', 'marital relationship enrichment' and 'couple enrichment' referring to the same services when provided to married couples (Commerford \& Hunter, 2016; Masoumi, Khani, Kazemi, Kalhori, Ebrahimi \& Roshanaei, 2017; Stanley, Allen, Markman, Rhoades \& Prentice, 2010). Recent literature, however, clarifies differences between concepts, while acknowledging the existing overlaps in terms of goals, strategies and target groups (Markman \& Rhoades, 2012; Karam, Antle, Stanley \& Rhoades, 2015). Sauerheber and Ponton (2018) describe ME as a wellness-based approach to strengthening key areas of marital success, while Sager and Sager (2005) describe ME as a systematic effort to improve the functioning of couples' marital relationship, or a 'well-established educational approach' to strengthening marriages. Govender (2008) adds the dynamic of ME as a preventative intervention developing and building on the couple's own resources and strengths, teaching social and interpersonal skills in order to enhance marital relationships. To summarise, ME includes an educational, systematic and well-planned approach based on wellness and prevention, with the aim of strengthening or improving the marital relationship.

The movement to enrich marriages began in Spain in 1962 by Father Gabriel Calvo (Bowling, Hill \& Jencius, 2005). Through his "Marriage Encounter", Father Gabriel Calvo had the intention to strengthen marriages through organised activities undertaken over a weekend (Sauerheber \& Ponton, 2018). The last three decades saw numerous ME programmes focusing on a range of phenomena, for example adjustment, satisfaction, communication skills, needs, intimacy, friendship, family of origin, issues, empathy, commitment, forgiveness, negotiation, trust, emotional literacy, respect, power and control, compromise, finances, self-awareness, anger, stress management, roles, values as well as beliefs (Kalkan \& Ersanli, 2008; Alqashan, 2008; Miller et al., 2014; Sauerheber \& Ponton, 2018) to equip couples with the skills needed to create satisfying relationships (Deacon \& Sprenkle, 2001). Other interventions focuses on marriage and couple conflict-resolution skills or strategies (Askari, Noah, Hassan \& Baba, 2012; Rogge, Cobb, Lawrence, Johnson \& Bradbury, 2013; Tosun \& Dilmac, 2015; Farero, Springer, Hollist \& Bischoff, 2015; Fernet, Hébert \& Paradis, 2016). What becomes clear is curricula for ME programmes may vary according to the needs of the target couples. Types of formats include lectures, psycho-educational groups, small group activities, one-on-one mentoring, retreat weekends, weekly or monthly meetings, and yearly booster sessions (Deacon \& Sprenkle, 2001; Sauerheber \& Ponton, 2018). Techniques include modelling, rehearsal of behaviours, encouragement and reinforcement (Bowling et al., 2005) as well as mirroring, validating and empathising (Schmidt et al., 2016; Mikle, 2016; Holliman, Muro \& Luquet, 2016; Shuper Engelhard, 2018). Delivery models and the level of training required for facilitation also vary from lay volunteers to mental health professionals (Sauerheber \& Ponton, 2018). A growing trend is to make use of self-directed relationship programmes available online or as self-help books and DVDs (Commerford \& Hunter, 2016). An example is the "PREPARE/ENRICH" programme enabling couples activities to be completed online (Honickman, 2014). Mostly the facilitator chooses what is relevant, so the challenge is to find a format suitable for the target (Dyer \& Dyer, 2002).

Along with ME, a range of marriage aid-rendering services is available to couples at the pre-marital, marital and post-marital stages, namely 'marriage preparation', 'marriage counselling', 'marriage guidance' as well as 'divorce counselling'. 'Marriage preparation' entails couples being educated and equipped before getting married to prevent and deal with potential challenges experienced in the relationship (Olson, Olson \& Larson. 2012; Killawi et al., 2018; Haselau, Kasiram \& Simpson, 2015; Duncan, Rogers \& McAllister, 2017). 'Marriage guidance' entails help provided in this instance to couples in order to encourage self-awareness, independence, making choices and adequate response to life challenges (Ansah-Hughes \& Practice, 2015). If post-marriage couples are distressed, but have not yet reached the point of divorce, 'marriage counselling' also known as 'marital therapy' with a goal of saving the relationship may be sought (Pierce, 2016; Stanley et al., 2010). Marriage counselling aims to strengthen the marital bond between spouses (Adams, 2007), helping them to increase the health of the 
relationship and become less distressed (Stanley et al., 2010). Next, 'divorce counselling' focuses on a deteriorating marital bond, with the ultimate goal of dissolving the relationship (Adams, 2007). Lastly, intervention provided to couples and/or family members going through divorce constitute 'pre-divorce counselling', while interventions provided after having finalised a divorce constitute 'post-divorce counselling' (Chang, 2016; Abubakar, Tabitha \& Bodinga, 2017).

\section{Overview of national and international ME programmes}

Two SA-based programmes PREPARE/ENRICH, IMAGO: Getting The Love You Want (GTLYW), and two international programmes Prevention and Relationship Enhancement Programme (PREP 8.0) and Couples Communication Program (CCP), are discussed.

\section{Prepare/enrich}

Origin: The PREPARE inventory was developed by David Olson in 1977, whereas the 'ENRICH' inventory was developed in 1981 by David Olson, David Fournier and Joan Druckman at Life Innovation Inc. in Minnesota (Olson, Legg, \& Hasle, 2012; Hasankhani \& Vatankhah, 2016; Li, 2015). Foci: Broadly considered as a prominent relationship inventory based on systems theory (Olson \& Olson, 1997), PREPARE/ENRICH', provides couples with necessary skills to improve their relationship (Olson et al., 2012; Hasankhani \& Vatankhah, 2016). During exercises significant issues are discussed, namely communication, sex and affection in a relationship, to name a few (Olson \& Olson, 1997) and individual feedback from a trained counsellor is provided (Olson et al., 2012; Hasankhani \& Vatankhah, 2016).

Format: Couples are given inventories to answer and later discuss with the facilitator. Furthermore, a customised totally online version of the programme is available (Olsen et al., 2012, Honickman, 2014).

Target audience: Dating, engaged and married couples (Olsen et al., 2012; Honickman, 2014).

Content described briefly: The PREPARE inventory goal is to assist premarital couples to prepare for marriage, whereas the ENRICH inventory focuses on enriching married couples by enhancing awareness of strengths and potential areas for growth (Olson et al., 2012; Hasankhani \& Vatankhah, 2016; Li, 2015). Core scales include discussions on communication, conflict resolution, financial management, leisure activities, affection, sexuality, partner style and habits, family, friends, relationship roles and spiritual beliefs (Olson et al., 2012); building of strengths, working on growth, family of origin and goal setting (Bowling et al., 2005).

Outcome/effectiveness: The PREPARE/ENRICH has been used in various research studies and found to have high reliability and validity (Bowling et al., 2005) and large national norms with couples from various ethnic groups (Olson et al., 2012). Hasankhani \& Vatankhah (2016) in a study evaluating the effectiveness on subjective well-being and sexual self-efficacy of couples in Iran concluded PREPARE/ENRICH was effective. Though over the short term, Schmidt et al. (2016) found PREPARE/ENRICH showed significant increase in couples' relationship satisfaction and communication skills after attending the workshop. Although the programme is rendered in SA, there is no evidence to validate success (Swart, 2013; Govender, 2008). PREPARE/ENRICH provides couples with the necessary skills to improve their relationship. During exercises individual feedback from a trained counsellor is provided (Olson et al., 2012; Hasankhani \& Vatankhah, 2016).

\section{Getting the love you want (GTLYW)}

Origin: Getting The Love You Want (GTLYW), based on IMAGO, was developed by Harville Hendix and Helen LaKelly Hunt at the Perkins School of Theology, Southern Methodist University (Holliman et al., 2016; Hendrix, Lakelly Hunt, Luquet Carlson, 2015; Hendrix, 1996).

Foci: Unique in creating awareness about traits experienced in childhood affecting mate selection, possibly fuelling present frustration and arguments (Schmidt et al., 2016). What resonates with many couples is learning together how to resolve childhood issues, accept one is born into, wounded and healed in a relationship (Khalili \& Afkari, 2017).

Format: GTLYW is provided in a three-day weekend workshop conducted away from home, serving as an advantage as couples get to be away from their daily routines (Schmidt et al., 2016). 
Target audience: married and unmarried couples.

Content described briefly: based on the IMAGO couples relationship therapy, GTLYW is an educational programme of about 20 hours (Hendrix, 1993) delivered worldwide by trained and certified facilitators (Schmidt et al., 2016), GTLYW is based on disciplines namely, the attachment theory, developmental psychology behavioural change techniques and neuroscience (Hendrix et al., 2015). Couples are taught and practice a communication skill referred to as 'couples dialogue'; or 'couples IMAGO dialogue'. The aim is to increase positive relational patterns (Schmidt et al., 2016), regulating anxiety to being fully able to listen to each other in an authentic, intentional atmosphere (Hendrix et al., 2015). Besides attentive listening, dialogue includes mirroring, validating and empathising with what the partner says (Schmidt et al., 2016; Mikle, 2016; Holliman et al., 2016). According to the IMAGO model, good communication together with empathetic connection brings about healing in a relationship (Holliman et al., 2016). The dialogue technique fosters a feeling of safety, through meaningful communication, improved listening, better conflict-resolution skills and a deepened connection with, understanding of, and insight into each other (Swart, 2013).

Outcome/effectiveness: IMAGO relationship therapy has been practised in SA for over a decade, with evidence of some aspects of communication and the quality of relationship improving after attendance (Swart, 2013). Hill and Perkel (2011) theorised the IMAGO relationship model as having been influential in the development of couples work specifically with private therapists in South African metropolitan cities such as Cape Town, Durban and Johannesburg. In a study on Zulu culture, Haselau et al. (2015) maintain IMAGO relationship therapy demonstrates that reciprocity is fundamental to the 'African worldview', whereas other aspects - for instance, IMAGO dialogue - would require to be adapted for relevance. Although research on the efficacy of IMAGO model is progressing and promising worldwide (Muro et al., 2016b; Schmidt et al., 2016; Muro et al., 2016a) there is a limitation with regard to empirical validation (Holliman et al., 2016; Patterson, 2017; Schmidt et al., 2016; Jakubowski, Milne, Brunner \& Miller, 2004). Lawson (2008) identified a similar limitation in SA despite IMAGO relationship therapy's long implementation.

\section{Prevention and relationship enhancement programme (PREP)}

The Prevention and Relationship Enhancement Programme (PREP) was developed in the 1990s by Howard Markman (Mujoko, 2013; Stanley, Markman, Jenkins, N. Erlacher, Eggar \& Ramos, 2017; Jacobi, 2017) at Denver University.

Foci: PREP is unique as it is both theory- and research-based (Mujoko, 2013; Stanley et al., 2017; Jacobi, 2017) and emphasises the importance of empirical data to describe the nature of the relationship problem, evaluate causal factors and demonstrate the effectiveness of intervention strategies (Stanley et al., 2017). Much emphasis and more time is allocated to participant discussions, experiences, activities and skills training rather than lecturing, thus allowing couples to learn from each other.

Format: a newer version, PREP 8.0 is modular-based, allowing each module to be taught independently, in any order considering the needs of couples as well as time factors (Stanley et al., 2017). PREP 8.0 includes use of video and music, and can be implemented with small and large groups as well as for individual couples (Stanley et al., 2017).

Target audience: PREP 8.0 was designed for engaged, married and cohabiting couples (Stanley et al., 2017).

Content described briefly: PREP is a psycho-educational prevention programme for couples (Allen, Rhoades, Markman \& Stanley, 2015; Stanley et al., 2017) and is similar to the standard PREP as it is based on a cognitive-behavioural curriculum focusing on helping couples identify thoughts and behaviours likely to influence the success of the relationship (Stanley et al., 2017). The curriculum builds on the assets of the older version, originally emphasising empirical foundations in relationship education. Furthermore, the curriculum builds on existing strengths as well as on critical life and relationship skills designed to help create more stable relations and better environments (Stanley et al., 2017). Five core themes of PREP 8.0 are 1) safety, 2) keys to success, 3) successful communication and conflict management, 4) self-reflection and awareness, and 5) protecting and nurturing the positive. 
Outcome/effectiveness: When follow-ups were made, the PREP approach was identified as an effective ME programme with long-term outcomes (Swart, 2013; Fallahchai et al., 2017; Jacobi, 2017). In addition, the PREP curriculum is simple, understandable, practical and effective in increasing marital satisfaction levels (Fallahchai et al., 2017), consequently linked to lower divorce rates (Jacobi, 2017). Despite empirical data supporting the effectiveness with regard to marital satisfaction in specific countries located in North America, Australia and Europe, Fallahchai et al. (2017) noted PREP evaluations studies have not been widely expanded to other societies, which is a limitation.

\section{The couples communication programme (CCP)}

The Couples Communication Programme (CCP) was developed by Sherod Miller, Elam Nunnally, and Daniel Wackman, at the University of Minnesota, Family Study Center (Sharifian, Najafi, \& Shaghaghi, 2011; Jacobi, 2017).

Foci: CCP is theoretically based in a systems approach and is one of the most researched ME programmes (Sharifian et al., 2011; Jacobi, 2017). Through developing clear, direct and open communication between partners, the goal of CCP is to raise awareness of the self and the partner, the relationship, conflict and communication styles (Jakubowski et al., 2004; Jacobi, 2017).

Format: CCP is conducted through structured didactic presentations followed by skills practice exercises (Jakubowski et al., 2004). The programme is presented to individual couples in six 50minutes sessions or to small and large groups of couples in four 2-hour sessions (Jacobi, 2017).

Target audience: dating, married and unmarried couples.

Content described briefly: Relationship strengthening skills beneficial to couples, namely caring about self, caring for a partner, resolving conflicts and mapping issues as well as relevant communication styles are taught (Sharifian et al., 2011).

Outcome/effectiveness: Based on available outcome research literature, CCP is considered an efficacious programme (Jakubowski et al., 2004) in terms of improving positive communication and greater relationship satisfaction (Sharifian et al., 2011). A limitation of the CCP is the consistent trend towards deterioration of relationship skills at follow-up, thus requiring further investigation for longterm effects (Jakubowski et al., 2004; Jacobi, 2017).

\section{THEORIES UTILISED AS BASIS FOR COUPLES AND SOCIAL WORK PRACTICE}

Since theory is a prediction of what can or might happen in certain situations given certain circumstances, it becomes integral in giving guidance to the way people are viewed and understood in social work practice (Teater, 2014). Theories suggested by the literature, and often utilised as the basis for interventions in couples and social work practice, are: family systems, attachment, cognitivebehaviour therapy, bio-ecological systems, strengths-based, social leaning and programme development theory.

\section{Family systems theory}

Marriage, just like a family, is a system (Sharf, 2012). From a family systems perspective, each family functions interdependently from other systems within the same environment, for example, a neighbourhood, a town and country, ultimately influencing each other (Sharf, 2012). Systems theory implies marriage, since it is a system dependent on or connected to other larger systems; it cannot be fully understood without first understanding how it functions as a whole and what its relationship is to other systems within the same environment (Sharf, 2012). Based on the perspective of marriage being a system, a couple's relationship is always changing due to environmental inputs, affecting couple's roles and ultimately influencing change in the entire system (Govender, 2008). Since marriage in most African societies is based on cultural practices (Mataboge et al., 2015), verifying the interdependence on other systems (Fairfax, 2014), the family systems theory allows for marriage to be viewed in context. The family system theory can thus provide a point of departure for developing a culturallyappropriate ME programme. 


\section{Attachment theory}

Described as a theory of relationships (Mujoko, 2013), attachment theory maintain that early experiences with primary caregivers are critical as they have an influence on human emotional and cognitive development, affecting adult behaviour (Xu \& Xue, 2014; Mikulincer \& Shaver, 2012; Fonagy, Luyten, Allison \& Campbell, 2018; Teater, 2014; Bowlby, 2012). A person develops cognitive representations (working models) at an early age based on experiences with caregivers (Hall, 2015). Similarly, when a child is not experiencing love from the caregiver during the early stages of development, the child is likely to internalise 'not being loved' and in turn may develop a negative perception of self as not worthy of love (Turner, 2017). As a result beliefs, attitudes and behaviours regarding intimate relationships may be influenced by negative perceptions based on existing internal working models developed at an early age (Hall, 2015). Shaver and Mikulincer (2014) confirm this by stating that human attachment needs are active from infancy to late adulthood and thus into adult romantic relationships (Xu \& Xue, 2014). According to Shaver and Mikulincer (2014), sustained romantic love in adulthood involves an emotional attachment conceptually parallel to an infants' emotional bond with the primary caregivers.

Attachment theory helps clarify needs and the types of beliefs couples hold about relationships (Hall, 2015). Attachment theory therefore, when applied to adult relationships, assumes that adults go into relationships with a history of experiences, memories, beliefs, and expectations influencing how they think, feel and behave in a relationship (Mujoko, 2013). Simply put, attachment theory provides a context to understand how the family of origin influences family members' future relationships (Hall, 2015).

\section{Cognitive-behavioural theory}

Commonly known as cognitive-behaviour therapy, as cognition influences feelings and behaviour, which can however be altered to mediate behavioural change (Dobson \& Dozois, 2019). Simply put, cognitive behaviour therapy maintains people can change the way they feel, if they change the way they think (Turner, 2017). In addition, according to cognitive therapists, beliefs about various aspects of life including marriage are formed in early childhood and develop throughout life, thus influencing future decisions (Sharf, 2012). Consequently, changing people's negative beliefs and thoughts forms part of its goals (Forstmeier, Maercker, Savaskan \& Roth, 2015). Cognitive-behavioural theory therefore implies people have the potential to actively shape their future by making decisions to respond positively to events and triggers previously experienced in life (Weaver, Himle, Steketee \& Muroff, 2014).

Cognitive-behavioural theory for work with couples was developed by Albert Ellis and his colleagues, and is now referred to as cognitive-behavioural couples theory (Weaver et al., 2014). Recognising the influence cognition has in intimate relationships, dysfunctional relationships result from the unrealistic beliefs couple hold about the relationship (Sharf, 2012). Cognitive-behavioural theory claims that by learning more adaptive behaviours, more rewarding behaviours are triggered (Turner, 2017).

Cognitive-behavioural couples theory is influenced by overlapping systems and theories pertaining to ecological models of relationship functioning and strengths-based perspectives (Weaver et al., 2014). Theories not taken in isolation provide the possibility to be integrated with other relevant theories to form a strong theoretical base for developing a culturally-appropriate ME programme.

\section{Bio-ecological systems theory}

Rosa and Tudge (2013), referring to the work of Bronfenbrenner (1994), state the family is an institution, playing an important role in influencing the development of individuals. Similar to attachment and cognitive-behavioural theories, the bio-ecological systems theory holds that a person's immediate environment has an influence on their development (Rosa \& Tudge, 2013). In case of marriage, if an individual person is raised in a healthy family set-up, he/she has a better chance of becoming a better spouse later in life. Still, at a macro-level Bronfenbrenner (1994) maintains the family, environment and culture or subculture, with particular reference to belief systems, bodies of 
knowledge, materials, resources, customs and life-style, also play an important role; for example, the way in which culture and belief systems can influence an individual's choice of a partner. In conjunction with the family systems theory, this theory provides a lens with which to view marriage between two people 'not in isolation, but in relation to other key factors, for instance, politics, current social issues and the history within the context' is provided (Bronfenbrenner, 1994).

\section{Strengths-based theory}

Strength-based approaches are increasingly used in disciplines such as nursing and social work, to name a few (Gan \& Ballantyne, 2016; Zastrow, 2016; Gottlieb, 2014; Franklin, 2015) and highlights people's abilities, values, interests, resources, beliefs, achievements and future aspirations (Zastrow, 2016). According to Hammond and Zimmerman (2010), the strength-based theory does not deny the existence of problems that people experience, but rather acknowledges and validates existing problems by identifying and highlighting strengths in dealing with same problems. Strength-based theory shifts the focus from deficits and problems by placing the emphasis on strengths, capacity for growth, resilience and hope (Lietz, 2011). Pattoni (2012) adds that strength-based theory concentrates on the inherent strengths of individuals, families, groups and organisations to aid recovery and empowerment. Olson et al. (2012) highlight the advantages of a strength-based theory, fundamental for a strong relationship; knowledge of their strengths helps couples to cope and manage stress, resorting to dormant skills probably utilised in times of need. Although the literature on the effectiveness of strength-based theory is increasing, there is a limitation regarding practice-based evidence (Franklin, 2015).

\section{Social learning theory}

Social learning theory suggests human behaviour is firstly learned when individuals interact with the environment; secondly, it can be predicted; and thirdly, it can be modified by altering behaviour through learning (Tarsono, 2018). People can learn by observing others (McCullough Chavis, 2011; Hutchinson \& Oltedal, 2014). Problematic behaviour can be changed by identifying and understanding what factors contributed to its formation and maintenance (McCullough Chavis, 2011). Based on the principles of social learning theory, when positive behaviours are reinforced, the relationship quality improves, whereas reinforcing negative behaviours causes a relationship to deteriorate (Johnson \& Bradbury, 2015). Consequently, the use of observational learning, imitation or modelling becomes important (Johnson \& Bradbury, 2015). Yang, Tian, Fang, Lu, Wei and Yi, (2017) summarise social learning theory as a 'cumulative and cyclic process' of several years of training and practice. Since ME is defined as an 'educational approach' (Bowling et al., 2005), social learning theory becomes primary and relevant in developing an ME where couples learn new skills to improve their relationship. Based on the social learning theory perspective, incorporating culture becomes central since learning occurs within the context of culture and shapes human behaviour and the social environment (McCullough Chavis, 2011).

\section{Programme development theory}

Programme theory firstly describes a specific programme, explaining why, how and under what circumstances effects will occur; secondly, it predicts outcomes; and thirdly, it stipulates the necessary requirements to bring about the desired effects (Sharpe, 2011; Maden, Cunliffe, Mcmahon, Booth, Carey, Paisley, Dickson \& Gabbay, 2017). In essence, programme theory provides the central motivation and describes the underlying factors for success (Olsen et al., 2012). Reed, Burton, RycroftMalone, Sackley and Walker (2014), support the effective design, execution and evaluation of quality improvement initiatives. Typically, a programme is built on a logical sequence of inputs, activities, outputs and subsequent short- and long-term effects (Olsen et al., 2012). Once programme theory is developed, it guides the collection, analysis and synthesis of data leading to the development of tested theoretical accounts of the desired intervention, implementation and impacts (Masterson-Algar, Burton, Rycroft-Malone, Sackley \& Walker, 2014). 


\section{SOCIAL WORK MODELS UTILISED AS BASIS FOR COUPLE WORK}

Models are frameworks setting out a clear sequence of actions to take during a complicated situation, thus helpful for social workers during practice (Payne, 2014). Social work practice models were reviewed, namely 'problem-solving', 'task-centred', 'cognitive-behavioural' and 'solution-focused' models based on applicability of culturally-appropriate ME programmes for the Black African married couples.

\section{Problem-solving model}

The problem-solving model is a component of cognitive behaviour therapy and an attempt to discover effective responses for problems (Dattilio \& Van Hout, 2006; Suso-Ribera, Camacho-Guerrero, Mccracken, Maydeu-Olivares \& Gallardo-Pujol, 2016), requiring first an understanding of the details of the problem before the best solution can be used (Turns, Eddy \& Jordan, 2016; Addelyan Rasi, Moula, Puddephatt \& Timpka, 2013). The effectiveness of the problem-solving approach lies in empowering people to resolve not only current but future problems also (Addelyan Rasi et al., 2013; Coady \& Lehmann, 2016).

\section{Task-centred model}

The task-centred model is used as a social work practice model with individuals, couples, groups and families in various contexts (Kelly, 2013). Central is partnership and empowerment values building on people's strengths, providing help rather than treatment Doel \& Marsh, 2017). The task-centred model builds on the belief that the accomplishment of small tasks (Doel \& Marsh, 2017) enhances confidence and self-esteem, with success experienced when people voluntarily choose what they want to achieve (Rooney \& Mirick, 2018, Kelly; 2013), and is mostly used when developing ethnically sensitive interventions (Doel \& Marsh, 2017). But as a problem-focused approach, it risks focusing on managing problems rather than on constructing ways to reach the goals (Mattaini, 2012).

\section{Cognitive-behavioural model}

The cognitive-behavioural model emphasizes ways to restructure cognition and learn better coping skills focusing on the present rather than highlighting long-term personality change and unresolved childhood issues (Rubin \& Babbie, 2016). The cognitive behavioural model is thus relevant in a context of ME programmes where the focus is on teaching couples new skills, adaptive actions, ultimately triggering more rewarding behaviours (Turner, 2017).

\section{Solution-focused model}

The solution-focused model assumes human beings are inherently motivated to reach their full potential, thus capable of solving their own problems (Parry, 2019). Emphasis is placed on assisting clients to construct solutions rather than solve problems (Gan \& Ballantyne, 2016), thus it is goal directed as well as future-oriented (Hogan, Hogan, Tuomola \& Yeo, 2016; Parry, 2019). The model advocates helping clients to imagine how they would like things to be in the future and what it would take to get there despite the existing challenges (Turns et al., 2016). Practitioners and clients work together to identify, define and meet needs, instead of dwelling on the past (Gan \& Ballantyne, 2016). The solution-focused model is thus relevant in a context of ME programmes since the focus is not on problems couples the experience, but rather on prevention of future problems (Govender, 2008).

\section{SUMMARY}

This literature review explored the nature of ME, national and international ME programmes, couples theories and social work models. The aim was to provide a narrative literature-informed overview of what existing ME programmes, couple theories and social work models for possible use as a basis to develop a culturally-appropriate ME programme for Black African married couples. Previous literature on local ME programmes focused mostly on English- and Afrikaans-speaking couples (Swart, 2013; Govender, 2008). This review focusses specifically on interventions for Black African married 
couples. Although a number of ME programmes exist both locally and internationally, four (PREPARE/ENRICH, GTLYW, PREP 8.0, CCP) were reviewed in terms of origin, focus, format, target audience, content and effectiveness, which may be summarised in short:

- Firstly, PREPARE/ENRICH and GTLYW are not culturally appropriate for the SA Black African population since programmes are based on Western models (Govender, 2008) and attract mostly English- and Afrikaans-speaking couples (Swart, 2013). On the other hand, PREP 8.0 and CCP, despite widespread use in many international societies, lack empirical data applicable to a SA context as no study could be found focusing specifically on Black African married couples.

- Secondly, the literature reveals a gap in empirical data evaluating the effectiveness of ME programmes within a SA context. Although PREPARE/ENRICH and GTLYW are widely utilised in SA (Swart, 2013; Govender, 2008) the programmes lack empirical data to support their effectiveness, particularly among couples from Black African cultures.

- Thirdly, a number of theories - namely family systems, attachment, cognitive-behavioural, bioecological systems, strength-based, social learning and programme development - are suitable to utilise as points of departure for the development of culturally-appropriate ME programmes for the Black African married couples. Family systems and bio-ecological system theories both explain how families and marriages are examples of systems interrelated with other systems pertaining to the environment, politics and culture; they are thus appropriate as to develop a culturally-appropriate ME programme viewing marriage as a system not in isolation, but in context. Attachment theory provides a context for understanding how families of origin influence future relationships, explaining types of beliefs couples hold about relationships (Hall, 2015), and clarifying likely needs. Cognitive-behavioural theory focuses on the impact of thinking and behaviour on an individual's personality. Similar to the attachment theory, cognitive-behavioural theory contends that beliefs about various aspects of life, for example, marriage, are formed during early childhood and develop throughout life, therefore influencing future decisions (Sharf, 2012). Strength-based theory focuses on highlighting strengths in dealing with existing problems (Hammond \& Zimmerman, 2010) of individuals, and is thus applicable when developing and building on the couple's own resources and strengths in order to enhance marital relationships (Swart, 2013; Govender, 2008). Social learning theory emphasises that human behaviour is learned (Hutchinson \& Oltedal, 2014; McCullough Chavis, 2011) and therefore can be predicted, modified, and reinforced (Tarsono, 2018; Johnson \& Bradbury, 2015). Since ME can be used as an educational approach (Bowling et al., 2005), it can be argued, based on the social learning theory, that couples can also be taught to learn new skills necessary for a functional relationship. Furthermore, programme development theory describes a specific programme, explains why, how and under what circumstances effects will occur, predict outcomes and stipulate the necessary requirements to bring about the desired effects (Sharpe, 2011; Maden et al., 2017). Identified theories are useful, because they present various perspective on marriage. Instead of treating theories in isolation, integrating them to form a strong base is necessary, because only limited literature incorporating relevant and effective theories into practice with specific reference to marriages is available.

- Fourthly, marriage is in itself a system connected to other societal structures (Sharf, 2012) and in most African societies is founded on cultural practices (Fairfax, 2014). While various couples theories are important in developing ME programmes in general, theories recognising marriage as a system involving two people and constantly influenced by other societal structures pertaining to family, culture and environment are fundamental.

- Fifthly, social work models - namely problem-solving, task-centred, cognitive-behavioural and solution-focused models - are suitable as points of departure for the development of culturallyappropriate ME programmes for Black African married couples. The problem-solving model is suitable for teaching couples skills to effectively resolve both current and with future problems (Addelyan Rasi et al., 2013; Coady \& Lehmann, 2016). The task-centred model, due to its focus on building strengths, encourages partnership and provides help rather than treatment or focusing on 
problems (Doel, 1993). The cognitive-behavioural model emphasises ways to restructure cognition and learn better coping skills focusing on the present rather than the past (Rubin \& Babbie, 2016). The solution-focused model also helps couples to construct solutions rather than dwelling on existing or previous problems (Gan \& Ballantyne, 2016).

After a thorough review PREP 8.0, an internationally-based programme, has been identified as most suitable to be used in the development of a culturally-appropriate ME programme for Black African married couples due to its international efficacy and reputation. PREP 8.0, compared to other programmes reviewed and as it is tested empirically, is effective over the long term (Jakubowski et al., 2004; Swart, 2013; Fallahchai et al., 2017). PREP 8.0 is skills-based, flexible, can be implemented in six 2-hour sessions, in group format, making it suitable to implement over a weekend (Fallahchai et al., 2017). However, utilisation of skills places the focus on general couples' relationship skills without specific consideration of the cultural context. Therefore, the PREP 8.0 programme cannot be used in its entirety; however, the programme is suitable to be adapted to incorporate a Black African cultural context. Therefore, interviews to gather baseline data regarding culture, needs and strengths to be integrated into a new programme must be conducted. Suggested questions could pertain to describing functional marriages according to specific customs; traditional and current beliefs on marriages, perceptions of stumbling blocks, strengths, current needs and practical recommendations for building a functional marital relationship.

Since it became clear that there are a number of ME programmes that are used both locally and internationally, it would be unnecessary to design a new programme from scratch. Instead, effective existing ME programmes supported through empirical data can be selected and adapted to the context of Black African married couples, in conjunction with research-based couple's theories.

Overall, it is clear that there are no culturally-appropriate and empirically evaluated ME programmes or interventions beneficial to Black African married couples in SA. The main findings reveal that theories recognize marriage as a system, therefore, acknowledgement of a variety of societal structures is fundamental, stressing the need for an appropriate integrative theory. Suitable empirically tested programmes (PREP 8.0 may be the most appropriate) and couple theories as well as social work models for integration are available for adaptation to specific contexts.

\section{RECOMMENDATIONS FOR AN ME PROGRAMME TO BE CULTURALLY APPROPRIATE FOR THE SA CONTEXT}

The findings of the review have important implications for practice as well as for further research. It is recommended that:

- Baseline information regarding cultural diversity in the functioning of marriage and couples' needs from various population groups can contribute towards suitable programme designs;

- The theoretical foundations of a culturally appropriate ME programme should recognise marriage as a system involving two people, but it is constantly influenced by other societal structures, for instance family, culture, politics and the environment;

- ME programme development and designs should be based on utilising the existing strengths of the target population to overcome future marital challenges rather than focusing on the weaknesses;

- Future research should explore and generate empirical data on the effectiveness of existing SAbased ME programmes, for example, the PREPARE/ENRICH and GTLYW to deal with the lack of culturally appropriate ME programmes in SA;

- More reviews and adaptations of Western empirically based ME programmes should be undertaken in order to meet the current needs of Black African married couples in SA;

- ME programmes in SA should be expanded to target couples from all racial and ethnic groups, particularly Black African married couples who are at risk of divorce; 
- More culturally-appropriate solutions in social work practice are recommended for supporting marriages especially within African cultures.

\section{CONCLUSION}

By developing an ME programme sustained by relevant theory, a gap in the literature can be filled, and the lack of support for ME programmes for Black African married couples can be addressed. Expanded knowledge, relevant for finding solutions within the field of social work, could be applicable to various Black contexts and lead to further research. By strengthening relationships and marriages, a positive effect on the overall stability and general wellbeing of Black African married couples, ultimately leading to stronger family structures, will hopefully be effected.

\section{REFERENCES}

ABUBAKAR, H., TABITHA, M. \& BODINGA, H. 2017. Psychosocial problems of adolescents from divorced homes: implications for counselling. International Journal of Topical Educational Issues, 1: 304-315.

ADAMS, J. F. 2007. Divorce therapy in context. Journal of Couple \& Relationship Therapy, 6: 109123.

ADDELYAN RASI, H., MOULA, A., PUDDEPHATT, A. J. \& TIMPKA, T. 2013. Empowering single mothers in iran: Applying a problem-solving model in learning groups to develop participants' capacity to improve their lives. British Journal of Social Work, 43: 833-852.

AGHAJARI, P., VALIZADEH, L., ZAMANZADEH, V., GHAHRAMANIAN, A. \& FORONDA, C. 2019. Cultural sensitivity in paediatric nursing care: A concept analysis using the Hybrid method. Scandinavian journal of caring sciences, 32: 118.

ALLEN, E. S., RHOADES, G. K., MARKMAN, H. J. \& STANLEY, S. M. 2015. PREP for strong bonds: A review of outcomes from a randomized clinical trial. Contemporary family therapy, 37: 232-246.

ALQASHAN, H. 2008. Enrichment training program and successful marriage in Kuwait: A field study on Kuwaiti couples. Digest of Middle East Studies, 17: 1-16.

ANSAH-HUGHES, W. \& PRACTICE 2015. The contribution of counselling providers to the success or failure of marriages. Journal of Education, 6: 50-55.

ANTLE, B., SAR, B., CHRISTENSEN, D., ELLERS, F., BARBEE, A. \& VAN ZYL, M. 2013. The impact of the Within My Reach relationship training on relationship skills and outcomes for lowincome individuals. The Journal of Marital and Family Therapy, 39(3), 346-357.

ASKARI, M., NOAH, S. B. M., HASSAN, S. A. \& BABA, M. 2012. Comparison the effects of communication and conflict resolution skills training on marital satisfaction. International Journal of Psychological Studies, 4: 182.

BEACH, S. R. H., HURT, T. R., FINCHAM, F. D., FRANKLIN, K. J., MCNAIR, L. M. \& STANLEY, S. M. 2011. Enhancing marital enrichment through spirituality: Efficacy data for prayer focused relationship enhancement. Psychology of Religion and Spirituality, 3: 201-216.

BETSCH, C. \& BÖHM, R. 2016. Cultural diversity calls for culture-sensitive health communication. Los Angeles, CA: SAGE Publications Sage CA.

BOWLBY, J. 2012. The making and breaking of affectional bonds. London: Routledge.

BOWLING, T. K., HILL, C. M. \& JENCIUS, M. 2005. An overview of marriage enrichment. The Family Journal, 13: 87-94.

BRADBURY, T. N. \& LAVNER, J. 2012. How can we improve preventive and educational interventions for intimate relationships? Journal of Behavior Therapy, 43: 113-122. 
BRONFENBRENNER, U. 1994. Ecological models of human development. Readings on the development of children, $2: 37-43$.

BYRNE, J. A. 2016. Improving the peer review of narrative literature reviews. Journal of Research integrity, $1,12$.

CAMPOS, B. \& KIM, H. S. 2017. Incorporating the cultural diversity of family and close relationships into the study of health. American Psychologist, 72: 543.

CHANG, J. 2016. Postdivorce Counselling and Dispute Resolution: Services, Ethics, and Competencies Counseling et résolution de conflits suite à divorce: services, éthique, et compétences. Canadian Journal of Counselling/Revue Canadienne de Counseling et de Psychothérapie, 50: 184-185.

CLIFFORD, A., MCCALMAN, J., BAINBRIDGE, R. \& TSEY, K. 2015. Interventions to improve cultural competency in health care for Indigenous peoples of Australia, New Zealand, Canada and the USA: a systematic review. International Journal for Quality in Health Care, 27: 89-98.

COADY, N. \& LEHMANN, P. 2016. Theoretical perspectives for direct social work practice: A generalist-eclectic approach. New York: Springer Publishing Company.

COMMERFORD, J. \& HUNTER, C. 2016. Marriage and relationship education. Family Matters, 97: $55-66$.

DATTILIO, F. M. \& VAN HOUT, G. C. 2006. The Problem-Solving Component in CognitiveBehavioral Couples' Therapy. Journal of Family Psychotherapy, 17: 1-19.

DEACON, S. A. \& SPRENKLE, D. H. 2001. A graduate course in marriage and family enrichment. Journal of marital and family therapy, 27: 251-260.

DEMARIA, R. M. 2005. Distressed couples and marriage education. Journal of Family Relations, 54: 242-253.

DOBSON, K. S. \& DOZOIS, D. J. 2019. Handbook of cognitive-behavioral therapies, London: Guilford Publications.

DOEL, M. 1993. Chapter 2: Task-centred work. London: Taylor \& Francis Ltd / Books.

DOEL, M. \& MARSH, P. 2017. Task-centred social work, New York: Routledge.

DONDERS, Y. M. 2015. Exploring the cultural dimensions of the right to the highest attainable standard of health. Potchefstroom Electronic Law Journal/Potchefstroomse Elektroniese Regsblad, 18(2): 179-222.

DUNCAN, S. F., ROGERS, M. A. \& MCALLISTER, S. 2017. Individual Personality and Emotional Readiness Characteristics Associated with Marriage Preparation Outcomes of Perceived Helpfulness and Change. Journal of Couple \& Relationship Therapy, 0:1-18.

DUNN, J. A. 2017. The contribution of the PREPARE program on marriages within the South African context. Pretoria: University of Pretoria.

DUPREE, W. J., BHAKTA, K. A., PATEL, P. S. \& DUPREE, D. 2013. Developing culturally competent marriage and family therapists: Guidelines for working with Asian Indian American couples. The American Journal of Family Therapy, 41: 311-329.

DYER, P. M. \& DYER, G. 2002. Planning and promoting marriage enrichment in the church. Journal of Family Ministry, 16: 41-45.

EBNER ERCEG, L. 2015. How culture-sensitive are your camp health services? Camping Magazine, 88: 12-14.

FAIRFAX, C. N. 2014. Social work, marriage, and ethnicity: Policy and practice. Journal of Human Behavior in the Social Environment, 24: 83-91. 
FALLAHCHAI, R., FALLAHI, M. \& RITCHIE, L. L. 2017. The impact of PREP training on marital conflicts reduction: A randomized controlled trial with Iranian distressed couples. Journal of Couple \& Relationship Therapy, 16: 61-76.

FARERO, A. M., SPRINGER, P., HOLLIST, C. \& BISCHOFF, R. 2015. Crisis management and conflict resolution: Using technology to support couples throughout deployment. Contemporary Family Therapy, 37: 281-290.

FERNET, M., HÉBERT, M. \& PARADIS, A. 2016. Conflict resolution patterns and violence perpetration in adolescent couples: A gender-sensitive mixed-methods approach. Journal of adolescence, 49: 51-59.

FERRARI, R. 2015. Writing narrative style literature reviews. Journal of Medical Writing, 24: 230235.

FONAGY, P., LUYTEN, P., ALLISON, E. \& CAMPBELL, C. 2018. Reconciling psychoanalytic ideas with attachment theory. New York: Guilford Press.

FOREHAND, R. \& KOTCHICK, B. A. 2016. Cultural Diversity: A wake-up call for parent training republished article. Behavior Therapy, 47: 981-992.

FORSTMEIER, S., MAERCKER, A., SAVASKAN, E. \& ROTH, T. 2015. Cognitive behavioural treatment for mild Alzheimer's patients and their caregivers (CBTAC): study protocol for a randomized controlled trial. Trials, 16, 526.

FRANKLIN, C. 2015. An update on strengths-based, solution-focused brief therapy. Journal of Health Social Work, 40: 73-76.

GAN, C. \& BALLANTYNE, M. 2016. Brain injury family intervention for adolescents: A solutionfocused approach. Neurorehabilitation, 38: 231-241.

GORDON, J. 2017. The voice of the social worker: A narrative literature review. British Journal of Social Work, 48: 1333-1350.

GOTTLIEB, L. N. 2014. Strengths-based nursing. The American Journal of Nursing, 114: 24-32.

GOVENDER, V. 2008. A description of content for a marriage enrichment programme. Johannesburg: University of Johannesburg. Thesis (MSc thesis)

GREGORY, A. T. \& DENNISS, A. R. 2018. An introduction to writing narrative and systematic reviews-Tasks, tips and traps for aspiring authors. Journal of Heart, Lung Circulation, 27: 893898.

HALL, S. S. 2015. Working models of marriage: An APPLICATION OF ATTACHMENT Theory. Marriage \& Family Review, 51: 713.

HAMMOND, W. \& ZIMMERMAN, R. 2010. A strengths-based perspective. [Online] Available: http://www.esd.ca/Programs/Resiliency/Documents/RSL_STRENGTH_BASED_PERSPECTIVE.pdf

[Accessed 03/05/2016].

HASANKHANI, S. \& VATANKHAH, H. 2016. The effectiveness of PREPARE-ENRICH Program on subjective well-being and sexual self-efficacy of Iranian Couples. International Journal of Humanities and Cultural Studies (IJHCS)ISSN 2356-5926, 3: 1849-1857.

HASELAU, C., KASIRAM, M. \& SIMPSON, B. 2015. African marriage counselling and the relevance of Western models of counselling. The Social Work Practitioner-Researcher, 27: 169-186.

HAWKINS, A. J. \& FACKRELL, T. A. 2010. Does relationship and marriage education for lowerincome couples work? A meta-analytic study of emerging research. Journal of Couple Relationship Therapy, 9: 181-191.

HENDRIX, H. 1996. The evolution of imago relationship therapy: A personal and professional journey. Journal of Imago Relationship Therapy, 1: 1-17. 
HENDRIX, H., LAKELLY HUNT, H., LUQUET, W. \& CARLSON, J. 2015. Using the imago dialogue to deepen couples therapy. Journal of Individual Psychology, 71: 253-272.

HENDRIX, H. H. 1993. Getting The Love You Want: A guide for couples. Winter Park: FL institute for image relation therapy.

HILL, A. \& PERKEL, A. 2011. With Greetings from South Africa: Couple work in South Africa: An historical overview from Cape Town. Couple and Family Psychoanalysis, 1: 235-241.

HOGAN, D., HOGAN, D., TUOMOLA, J. \& YEO, A. K. 2016. Solution focused practice in Asia. Taylor \& Francis.

HOLLIMAN, R., MURO, L. \& LUQUET, W. 2016. Common Factors between couples therapists and imago relationship therapy. A survey of shared beliefs, values, and intervention strategies. The Family Journal, 1066480716648693.

HONICKMAN, C. B. 2014. A proposed addition to the prepare/enrich marriage preparation program for adult children of divorce: A positive psychology and structural family systems approach. Chicago: The Chicago school of professional psychology (Doctoral dissertation).

HUTCHINSON, G. S. \& OLTEDAL, S. 2014. Five theories in social work. [Online] Available: http://brage.bibsys.no/xmlui/bitstream/id/96588/Hutchinson_GS.pdf. Universiteit in Nordland. [Accessed 05/06/2016].

JACOBI, L. 2017. A Preliminary investigation of empirically based and spiritually based marital enrichment programs. The Qualitative Report, 22: 1297-1314.

JAKUBOWSKI, S. F., MILNE, E. P., BRUNNER, H. \& MILLER, R. B. 2004. A review of empirically supported marital enrichment programs. Family Relations, 53: 528-536.

JOHNSON, M. D. \& BRADBURY, T. N. 2015. Contributions of social learning theory to the promotion of healthy relationships: Asset or liability? Journal of Family Theory \& Review, 7: 13-27.

KALKAN, M. \& ERSANLI, E. 2008. The effects of the marriage enrichment program based on the cognitive-behavioral approach on the marital adjustment of couples. Educational Sciences: Theory and Practice, 8: 977-986.

KARAM, E. A., ANTLE, B. F., STANLEY, S. M. \& RHOADES, G. K. 2015. The marriage of couple and relationship education to the practice of marriage and family therapy: A primer for integrated training. Journal of Couple \& Relationship Therapy, 14: 277-295.

KELLY, M. S. 2013. Task-Centered Practice. in Encyclopedia of Social work. USA: NASW Press and Oxford University Press.

KHALILI, N. J. \& AFKARI, F. 2017. The impact of imago therapy on couples' intimacy, burnout and love styles. QUID: Investigación, Ciencia y Tecnología, 108-116.

KILlAWI, A., FATHI, E., DADRAS, I., DANESHPOUR, M., ELMI, A. \& ALTALIB, H. 2018. Perceptions and experiences of marriage preparation among U.S. Muslims: Multiple voices from the community. Journal of Marital and Family Therapy, 44: 90-106.

LAWSON, W. A. 2008. Improving couple communication through the Imago Getting the Love You Want Workshop for Couples. Stellenbosch: University of Stellenbosch. (M Thesis)

LI, Z. 2015. Effects of PREPARE/ENRICH Couple Relationship Education for Chinese College Students in Heterosexual Exclusive Dating Relationships. Minnesota: University of Minnesota. (M Thesis)

LIETZ, C. A. 2011. Theoretical adherence to family centered practice: Are strengths-based principles illustrated in families' descriptions of child welfare services? Children and Youth Services Review, 33: 888-893. 
MADEN, M., CUNLIFFE, A., MCMAHON, N., BOOTH, A., CAREY, G. M., PAISLEY, S., DICKSON, R. \& GABBAY, M. 2017. Use of programme theory to understand the differential effects of interventions across socio-economic groups in systematic reviews - a systematic methodology review. Journal of Systematic reviews, 6: 266.

MAFELA, M. J. 2013. Cultural diversity and the element of negation. Intercultural Communication Studies, 22: 124-133.

MANDEL, I. 2017. Social Work and Social Service Providers. New York: Great Neck Publishing.

MARKMAN, H. J. \& RHOADES, G. K. 2012. Relationship education research: Current status and future directions. Journal of Marital Family Therapy, 38: 169-200.

MASOUMI, S. Z., KHANI, S., KAZEMI, F., KALHORI, F., EBRAHIMI, R. \& ROSHANAEI, G. 2017. Effect of marital relationship enrichment program on marital satisfaction, marital intimacy, and sexual satisfaction of infertile couples. International Journal of Fertility Sterility, 11: 197-204.

MASTERSON-ALGAR, P., BURTON, C. R., RYCROFT-MALONE, J., SACKLEY, C. M. \& WALKER, M. F. 2014. Towards a programme theory for fidelity in the evaluation of complex interventions. Journal of evaluation in clinical practice, 20: 445-452.

MAtaboge, M. S., NGUNYUlU, R. N., MOGALE, S., MULAUdZI, F. M. \& PEU, M. D. 2015. Culture and marriage: The dual barriers to condom use among health care providers in Tshwane, South Africa. African Journal for Physical, Health Education, Recreation \& Dance, 1: 291-305.

MATTAINI, M. A. 2012. From task-centered social work to evidence-based and integrative practice: Reflections on history and implementation. In: TINA L. RZEPNICKI, S.G.M., and HAROLD E. BRIGGS (ed). Chicago: University of Chicago Press.

MBUNYUZA-MEMANI, L. 2018. Wedding Reality TV bites black: Subordinating ethnic weddings in the South African black culture. Journal of Communication Inquiry, 42: 26-47.

MCCULLOUGH CHAVIS, A. 2011. Social learning theory and behavioral therapy: Considering human behaviors within the social and cultural context of individuals and families. Social Work in Public Health, 26: 471-481.

MEYER, A. 2005. Cross-cultural issues in ADHD research. Journal of Psychology in Africa, 10: 101-106.

MIKLE, K. S. 2016. African American couples: socio-cultural factors impacting marriage trends, reflections on marriageability, and a systematic review of culturally grounded couple and marriage relationship intervention.

MIKLE, K. S. \& GILBERT, D. J. 2019. A systematic review of culturally relevant marriage and couple relationship education programs for African-American couples. Journal of Ethnic \& Cultural Diversity in Social Work, 28:1, 50-57.

MIKULINCER, M. \& SHAVER, P. R. 2012. Adult Attachment orientations and relationship processes. Journal of Family Theory \& Review, 4: 259-274.

MILlER, R. B., NUNES, N. A., BEAN, R. A., DAY, R. D., FALCETO, O. G., HOLLIST, C. S. \& FERNANDES, C. L. 2014. Marital problems and marital satisfaction among brazilian couples. The American Journal of Family Therapy, 42: 153-166.

MUJOKO, R. 2013. The role of marriage preparation programs in preventing divorce: narratives of recently married individuals in Baffalo city municipality. Alice: University of Fort Hare. (M Thesis)

MURO, L., HOLLIMAN, R. \& LUQUET, W. 2016a. Imago relationship therapy and accurate empathy development. Journal of Couple Relationship Therapy, 15: 232-246. 
MURO, L., HOLLIMAN, R. \& LUQUET, W. 2016b. The Impact of the safe conversations workshop with diverse, low-income couples. The American Journal of Family Therapy, 44: 155-167.

NTULI, C. D. 2012. Intercultural misunderstanding in South Africa: An Analysis of Nonverbal Communication Behaviour in Context. Intercultural Communication Studies, 21: 20-31.

O'HALLORAN, M. S., RIZZOLO, S., COHEN, M. L. \& WACKER, R. 2013. Assessing the impact of a multiyear marriage education program. The Family Journal, (1066480713476849) 21: 328-334.

OLSEN, K., LEGG, S. \& HASLE, P. 2012. How to use programme theory to evaluate the effectiveness of schemes designed to improve the work environment in small businesses. Work, 41: 5999-6006.

OLSON, D. H. L. \& OLSON, A. K. 1997. Prepare/enrich program: version 2000. Journal of Family Ministry, 11: 28-54.

OLSON, D. H. L., OLSON, A. K. \& LARSON, P. J. 2012. Prepare-Enrich program: overview and new discoveries about couples. Family and Community Ministries, 25: 30-44

PARRY, S. 2019. The Handbook of brief therapies: A practical guide, Los Angeles: Sage Publications Limited.

PATTERSON, L. O. 2017. Romantic interest selection from an imago relationship therapy perspective. Statesboro: Georgia Southern University. (M Thesis)

PATTONI, L. 2012. Strengths-based approaches for working with individuals. United Kingdom: Institute for Research and Innovation in Social Services.

PAYNE, M. 2014. Modern social work theory. New York: Oxford University Press.

PIERCE, A. S. 2016. Perceived Impact of Prevention and Relationship Enhancement Program (PREP) on Marital Satisfaction. Minnesota: Walden University. (PhD Dissertation)

PILL, S. \& HARVEY, S. 2019. A narrative review of children's movement competence research 19972017. Physical Culture Sport. Studies Research at grassroots: for the social sciences and human service professions, 81: 47-74.

QUIRK, K., OWEN, J., INCH, L. J., FRANCE, T. \& BERGEN, C. 2014. The alliance in relationship education programs. Journal of marital family therapy, 40: 178-192.

REED, J. E., MCNICHOLAS, C., WOODCOCK, T., ISSEN, L. \& BELL, D. 2014. Designing quality improvement initiatives: the action effect method, a structured approach to identifying and articulating programme theory. BMJ Qual Saf, 23: 1040-1048.

ROGGE, R. D., COBB, R. J., LAWRENCE, E., JOHNSON, M. D. \& BRADBURY, T. N. 2013. Is skills training necessary for the primary prevention of marital distress and dissolution? A 3-year experimental study of three interventions. Journal of Consulting and Clinical Psychology, 81: 949.

ROONEY, R. H. \& MIRICK, R. G. 2018. Strategies for work with involuntary clients, New York: Columbia University Press.

ROSA, E. M. \& TUDGE, J. 2013. Urie Bronfenbrenner's theory of human development: Its evolution from ecology to bioecology. Journal of Family Theory \& Review, 5: 243-258.

RUBIN, A. \& BABBIE, E. R. 2016. Empowerment series: Research methods for social work, United States: Cengage Learning.

SAGER, D. E. \& SAGER, W. G. 2005. SANCTUS Marriage Enrichment. The Family Journal, 13: 212-218.

SAUERHEBER, J. D. \& PONTON, R. F. 2018. Building the marital muscle groups: A theory-based marriage enrichment approach program in a clinical practice setting. The Family Journal, 26: 11-21. 
SCHMIDT, C. D., LUQUET, W. \& GEHLERT, N. C. 2016. Evaluating the impact of the "Getting the love you want" couples workshop on relational satisfaction and communication patterns. Journal of Couple \& Relationship Therapy, 15: 1-18.

SHARF, R. S. 2012. Theories of psychotherapy and counseling concepts and cases, Canada, Brooks/cole, Cengage Learning.

SHARIFIAN, M., NAJAFI, S. \& SHAGHAGHI, F. 2011. An investigation of couple communication program (CCP) on the life's quality and intimacy of unsatisfied women. Procedia-Social and Behavioral Sciences, 30: 1991-1994.

SHARPE, G. 2011. A review of program theory and theory-based evaluations. American International Journal of Contemporary Research, 1: 72-75.

SHAVER, P. R. \& MIKULINCER, M. 2014. Attachment bonds in romantic relationships. Annual meeting of the American Psychological Association, Washington, DC.

SHISANA, O., RISHER, K., CELENTANO, D. D., ZUNGU, N., REHLE, T., NGCAWENI, B. \& EVANS, M. G. J. A. C. 2016. Does marital status matter in an HIV hyperendemic country? Findings from the 2012 South African National HIV Prevalence, Incidence and Behaviour Survey. 28: 234241.

SHUPER ENGELHARD, E. 2018. Embodying the couple relationship: kinesthetic empathy and somatic mirroring in couples therapy. Journal of Couple and Relationship Therapy. 18 (2), 126-147.

SPEIZER, I. S., ZULE, W. A., CARNEY, T., BROWNE, F. A., NDIRANGU, J., WECHSBERG, W. M. \& MEDICINE 2018. Changing sex risk behaviors, gender norms, and relationship dynamics among couples in Cape Town, South Africa: Efficacy of an intervention on the dyad. Journal of Social Science Medicine, 209: 95-103.

STANLEY, S. M., ALLEN, E. S., MARKMAN, H. J., RHOADES, G. K. \& PRENTICE, D. L. 2010. Decreasing divorce in US Army couples: Results from a randomized controlled trial using PREP for Strong Bonds. Journal of couple relationship therapy, 9: 149-160.

STANLEY, S. M., MARKMAN, H. J., JENKINS, N. H., ERLACHER, J., EGGAR, M. \& RAMOS, L. 2017. PREP 8.0 Leader guide. In: PREP EDUCATIONAL PRODUCTS, I. (ed). Colorado.

STATISTICS-SA 2014. Marriages and divorces 2014. Pretoria, South Africa.

STATISTICS-SA 2015. Marriages and divorces 2015. Pretoria, South Africa.

STATISTICS-SA 2016. Marriages and divorces 2016. Pretoria, South Africa.

STATISTICS-SA 2018. Mid-year population estimates 2018. Pretoria, South Africa.

SU, L. P., MILLER, R. B., CANLAS, J. M., LI, T.-S., HSIAO, Y.-L. \& WILLOUGHBY, B. J. 2015. A cross-cultural study of perceived marital problems in Taiwan and the United States. Contemporary Family Therapy, 37: 165-175.

SURMITIS, K. A., FOX, J. \& GUTIERREZ, D. 2018. Meditation and appropriation: Best practices for counselors who utilize meditation. Counseling Values, 63: 4-16.

SUSO-RIBERA, C., CAMACHO-GUERRERO, L., MCCRACKEN, L. M., MAYDEU-OLIVARES, A. \& GALLARDO-PUJOL, D. 2016. Social problem solving in chronic pain: An integrative model of coping predicts mental health in chronic pain patients. Journal of Health Psychology, 21: 1015-1025.

SWART, E. V. 2013. The needs of young Afrikaans speaking married couples for marriage enrichment programmes. Potchefstroom: North-West University. (M Thesis)

TARSONO, T. 2018. IMPLIKASI TEORI BELAJAR SOSIAL (SOCIAL LEARNING THEORY) DARI ALBERT BANDURA DALAM BIMBINGAN DAN KONSELING. Psympathic: Jurnal Ilmiah P:ikologi, 3: 29-36. 
TEATER, B. 2014. An introduction to applying social work theories and methods, United Kingdom: McGraw-Hill Education (UK).

TOSUN, F. \& DILMAC, B. 2015. Predictor relationships between values held by married individuals, resilience and conflict resolution styles: A model suggestion. Educational Sciences: Theory \& Practice, 4: 849-857.

TURNER, F. J. 2017. Social work treatment: Interlocking theoretical approaches, New York: Oxford University Press.

TURNS, B., EDDY, B. P. \& JORDAN, S. S. 2016. Working with siblings of children with autism: A solution-focused approach. Australian and New Zealand Journal of Family Therapy, 37: 558-571.

VALCHEV, V. H., NEL, J. A., VAN DE VIJVER, F. J., MEIRING, D., DE BRUIN, G. P. \& ROTHMANN, S. 2013. Similarities and differences in implicit personality concepts across ethnocultural groups in South Africa. Journal of Cross-Cultural Psychology, 44: 365-388.

VOSLOO, D. S. 2011. Understanding the role of culture during teaching and learning through English second language at a university of technology. Potchefstroom: North-West University. (M Thesis)

WEAVER, A., HIMLE, J., STEKETEE, G. \& MUROFF, J. 2014. Cognitive Behavioral Therapy. Oxford: NASW Press and Oxford University Press.

WORTHINGTON, E. L., JR., BERRY, J. W., HOOK, J. N., DAVIS, D. E., SCHERER, M., GRIFFIN, B. J., WADE, N. G., YARHOUSE, M., RIPLEY, J. S., MILLER, A. J., SHARP, C. B., CANTER, D. E. \& CAMPANA, K. L. 2015. Forgiveness-reconciliation and communication-conflict-resolution interventions versus retested controls in early married couples. Journal of Counseling Psychology, 62: $14-27$.

XU, L. I. \& XUE, Z. 2014. ADULT ATTACHMENT ORIENTATIONS AND SUBJECTIVE WELLBEING: EMOTIONAL INTELLIGENCE AND SELF-ESTEEM AS MODERATORS. Social Behavior \& Personality: An International Journal, 42: 1257-1265.

YANG, Y., TIAN, Y., FANG, J., LU, H., WEI, K. \& YI, L. 2017. Trust and deception in children with autism spectrum disorders: A social learning perspective. Journal of Autism \& Developmental Disorders, 47: 615-625.

ZASTROW, C. 2016. Empowerment Series: Introduction to Social Work and Social Welfare: Empowering People, USA: Cengage Learning. 